\title{
Decontamination of hexavalent chromium and tri-ethyl phosphate stimulants through photacatalytic oxidation
}

\author{
${ }^{1}$ M. Fathizadeh; ${ }^{2}$ H. Fakhraee; ${ }^{3} *$ A. Aroujalian \\ ${ }^{1}$ Department of Chemical Engineering, Amirkabir University of Technology, Tehran, Iran \\ ${ }^{2}$ Department of Civil Engineering, University of Science and Technology, Tehran, Iran \\ ${ }^{3}$ Department of Chemical Engineering, Food Process Engineering and Biotechnology Research Center, Amirkabir \\ University of Technology, Tehran, Iran
}

Received 27 December 2010; revised 9 March 2011; accepted 2 August 2011

\begin{abstract}
In this paper, the photocatalytic decontamination of hexavalent chromium and tri-ethyl phosphate, two important wastewater contaminants, are studied by the ultraviolet / nano-titanium dioxide process. The $\mathrm{pH}$ value and synergic effect between the oxidation of tri-ethyl phosphate and the reduction of hexavalent chromium were investigated in different concentrations of tri-ethyl phosphate and hexavalent chromium. Furthermore, the effects of ultraviolet and nano-titanium dioxide were investigated in a solution which contained tri-ethyl phosphate and hexavalent chromium. Results of adsorptions showed that hexavalent chromium was adsorbed better in acidic $\mathrm{pH}$ while the better adsorption for tri-ethyl phosphate was occurred in alkalinity $\mathrm{pH}$. The reduction rate of hexavalent chromium was higher in acidic solutions while it was obtained at natural $\mathrm{pH}$ for tri-ethyl phosphate. In co-adsorption of hexavalent chromium and triethyl phosphate pollutants, tri-ethyl phosphate slightly increased adsorption of hexavalent chromium, but hexavalent chromium had no influence on the adsorption of tri-ethyl phosphate on nano-titanium dioxide particles. In contrast, triethyl phosphate has an improving effect on the reduction reaction rate of hexavalent chromium which increases with the interaction of the concentration of tri-ethyl phosphate in mixture. The same is true for the oxidation rate of tri-ethyl phosphate.
\end{abstract}

Keywords: Adsorption; Kinetic reaction rate; Synergetic effect; Ultraviolet / Nano-Titanium dioxide process; Wastewater treatment

\section{INTRODUCTION}

Nowadays, an important environmental constrain is the effort to improve water quality and remove pollution from wastewater. This can be done through different physical, chemical and biological treatment processes. These processes are also being used for oxidizing, removing and mineralizing various surfaces and ground waters (Joseph et al., 2009; Ambashta et al., 2010; Sun et al., 2011). A novel method that has become popular in recent decades is the Advanced oxidation processes (AOPs) which are very potent in oxidization, decolorization, mineralization, reducing heavy metals and degrading organic pollutants (Atafar et al., 2010; Gharbani et al., 2010; Nouri et al., 2011). Due to the high oxidation rate of the chemical reactions caused by AOPs, the behavior of the chemicals is significantly

*Corresponding Author Email: aroujali@aut.ac.ir Tel.: +98 21 64543163; Fax: +98 216640584 affected after the treatment (Andreozzi et al., 1999; Bang et al., 2005; Gerven et al., 2007; Thiruvenkatachari et al., 2008).

Organophosphate is a very complicated contaminant in wastewater which contains insecticides, pesticides and detergents. These types of pollutants are found in industrial, agricultural and also domestic wastewater. Organophosphate degrades to several intermediate materials; phosphate appears as a solution when it is completely degraded. The Tri-ethyl phosphate (TEP) is an organophosphate which is used as an industrial catalyst, a polymer resin modifier, a plasticizer, an intermediate for pesticides and other chemicals, a stabilizer for peroxides, a strength agent for rubber and plastic including vinyl polymers and unsaturated polyesters, etc (Percherancier et al., 1995; Malato et al., 2000; Kozlova et al., 2004). TEP can be hydrolyzed and 
degraded to mono and diethyl phosphate which are more toxicant than TEP.

Heavy metals are also a significant environmental contaminant worldwide such as hexavalent chromium $\mathrm{Cr}(\mathrm{VI})$. $\mathrm{Cr}(\mathrm{VI})$ and trivalent chromium $\mathrm{Cr}(\mathrm{III})$ are two oxidation states of chromium, $\mathrm{Cr}(\mathrm{VI})$ is usually highly soluble and highly toxic and is a suspected carcinogen and mutagen (Wuana et al., 2010). In contrast, Cr(III) is relatively insoluble in an aqueous systems and exhibits no toxicity (Ku et al., 2001; Jiang et al., 2006; Xu et al., 2006). The wastewater of pesticide manufacture, including animal poisons, insecticides, fungicides and herbicides, commercially manufacturing, blending, mixing or formulating pesticides usually contain both Chromium and TEP (Chirwa et al., 2000; Kozlova et al., 2004).

Researchers have studied the photocatalytic oxidation of some organphosphorus pesticides (acrinathrin, methamidophos, malathion, diazion, carbetamide, and insecticide fenitrothion) (Kerzhentsev, et al., 1996; Doong and Chang, 1997; Kozlova et al., 2004). The main intermediates in the degradation of pesticides in wastewater have been studied by Percherancier et al. (1995). They reported that hydroxylated products and its derivatives as well as products of cycled though the side chain can be made. The intermediate material in the decomposition of some organophosphate was investigated by Kozlova et al. (2004). The pervious works show that final products of organophosphate degradation are phosphate, carbon dioxide and water. Moreover, several reports have been presented for the reduction of $\mathrm{Cr}(\mathrm{VI})$; the effects of important parameters such as $\mathrm{pH}$ values (Chirwa et al., 2000), titanium dioxide $\left(\mathrm{TiO}_{2}\right)$ dosage (Khalil et al., 1998), light intensities, dissolved oxygen levels and other operating conditions were investigated (Chenthamarakshan et al., 2000; Colon et al., 2001; Uyguner and Bekbolet, 2004; Wang et al., 2008). There is not any report on type of kinetic reaction rate and effect of different parameters on the TEP photocatalytic reaction rate. Also, there are TEP and $\mathrm{Cr}$ (VI) metals in some wastewater streams; therefore studying their adsoption, photocatalytic oxidation and synergic rate are something important and interesting which is yet to be done.

In this work, adsorption of $\mathrm{Cr}(\mathrm{VI})$ and TEP over the $\mathrm{TiO}_{2}$, the simultaneous decontamination of $\mathrm{Cr}(\mathrm{VI})$ and TEP by the UV/TiO 2 photocatalytic process and the possibility of synergic effect were investigated.
Furthermore, effects of $\mathrm{pH}, \mathrm{UV}$ radiation, $\mathrm{TiO}_{2}$ dosage and operation condition parameters on the TEP and $\mathrm{Cr}(\mathrm{VI})$ oxidation reaction rates were studied. At the end, the kinetic reaction rate for the TEP and $\mathrm{Cr}(\mathrm{VI})$ as a function of $\mathrm{pH}$ and initial concentration was obtained. This research has been done at Amirkabir University, Tehran on 2010.

\section{MATERIALS AND METHODS}

\section{Materials and analysis}

TEP with over $99.5 \%$ purity and potassium chromate $\left(\mathrm{K}_{2} \mathrm{CrO}_{4}\right)$ were obtained from Merck Co. (Germany). Titanium dioxide nano particle (P-25, ca. $80 \%$ anatase and $20 \%$ rutile) with an average particle size of $20 \mathrm{~nm}$ was supplied by Degussa, Germany.

The concentration of $\mathrm{Cr}(\mathrm{VI})$ was analyzed colorimetrically at a wavelength of $540 \mathrm{~nm} \mathrm{UV/visible}$ spectrophotometer (Cecil, CE 2501 model 2000, Instruments, UK) following the standard method with 1,5-diphenylcarbazide (Kim et al., 2001). The phosphate concentration was measured by a UV / visible spectrophotometer at a wavelength of $640 \mathrm{~nm}$. The gas chromatograph (GC) equipped with a flameionization detector equipped and a WCOT fused silica column $(50 \mathrm{~m} \times 250 \mathrm{im} \times 0.4 \mathrm{im})$ to measure the TEP concentration.

The specific surface area (BET method), specific pore volume and average pore diameter (BJH method) of the $\mathrm{TiO}_{2}$ nano particle determined by $\mathrm{N}_{2}$ adsorptiondesorption isotherms using a SORPTOMATIC 1990 Series instrument at $-196^{\circ} \mathrm{C}$. The X-ray diffraction (XRD) pattern was obtained using a Philips X'Pert diffractometer (X'pert diffractometer using $\mathrm{CuK}$ á radiation).

\section{Adsorption measurements}

The adsorption value measurements were carried out in a $200 \mathrm{ml}$ glass bottle with $40 \mathrm{mg} \mathrm{TiO}$ into $100 \mathrm{ml}$ aqueous solution containing $\mathrm{Cr}(\mathrm{VI})(40 \mathrm{mg} / \mathrm{L})$ and TEP $(30 \mathrm{mg} / \mathrm{L})$. The suspensions were continuously stirred under darkness for $4 \mathrm{~h}$ at a constant temperature of $25{ }^{\circ} \mathrm{C}$ under five different $\mathrm{pH}$ levels which were adjusted to desired values from 2 to 12 using a dilute solution of $\mathrm{HCl}(0.01 \mathrm{~N})$ and $\mathrm{NaOH}(0.01 \mathrm{~N})$. After absorption equilibrium, all samples were centrifuged, and then filtered through $0.2 \mathrm{im}$ Millipore syringe filters in order to remove the $\mathrm{TiO}_{2}$ particles. The remaining $\mathrm{Cr}$ (VI) and TEP were analyzed to obtain the percent of adsorption via calculation of the mass 
balance:

$\%$ adsorption percent $=\frac{C_{i}-C_{0}}{C_{i}} \times 100$

Where $\mathrm{C}_{\mathrm{i}}$ and $\mathrm{C}_{\mathrm{o}}$ are the concentrations of TEP and $\mathrm{Cr}$ (VI) $[\mathrm{mg} / \mathrm{L}]$ in the initial and final liquid, respectively.

\section{Study of photoreaction process}

The oxidation of TEP and $\mathrm{Cr}(\mathrm{VI})$ were carried out in a batch reactor shown in Fig. 1. The reaction mixture inside the glass bottle was maintained in suspension by shake. Six 15W UV-C lamps were used as a light source and the reactor temperature was stable by means of cooled water at $25.0 \pm 0.1{ }^{\circ} \mathrm{C}$. The concentration of $\mathrm{TiO}_{2}$ in the suspension was $0.4 \mathrm{~g} / \mathrm{L}$ containing $\mathrm{Cr}(\mathrm{VI})$ and TEP. The concentration of $\mathrm{Cr}(\mathrm{VI})$ and TEP was changed from 25 to $55 \mathrm{mg} / \mathrm{L}$ and from 10 to $50 \mathrm{mg} / \mathrm{L}$, respectively.

\section{RESULTS AND DISCUSSION}

Structure and surface characterization of $\mathrm{TiO}_{2}$

The volume and surface area of the $\mathrm{TiO}_{2}$ nano particle, as determined by $\mathrm{N}_{2}$-porosimetry were $0.15 \mathrm{~cm}^{3} / \mathrm{g}$ and $50.1 \mathrm{~m}^{2} / \mathrm{g}$, respectively. The surface characteristics and pore size value for the photocatalyst is shown in Table 1 . The X-ray diffraction (XRD) pattern of the nano- $\mathrm{TiO}_{2}$ are shown in Fig. 2 which exhibited strong diffraction peaks at $27^{\circ}, 36^{\circ}$ and $55^{\circ}$ (Tompsett et al., 1995; Zhang et al., 2000). Ordinary peaks were exhibited at $25^{\circ}$ and $48^{\circ}$ indicating that $\mathrm{TiO}_{2}$ was in the rutile and the anatase phase, respectively. The crystallite size of the prepared particles obtained from the XRD line broadening using Scherrer's equation is $20 \mathrm{~nm}$. The nitrogen adsorptiondesorption isotherm and the pore size distribution plot can be seen in Fig. 3 which had characteristics of a type II isotherm.

\section{Adsorption on $\mathrm{TiO}_{2}$ surface}

Adsorption of $\mathrm{Cr}(\mathrm{VI})$ on $\mathrm{TiO}_{2}$

The adsorption amounts of $\mathrm{Cr}(\mathrm{VI})$ by $\mathrm{TiO}_{2}$ particles at different $\mathrm{pH}$ values are shown in table 2 . The equilibrium adsorption capacity of $\mathrm{Cr}(\mathrm{VI})$ on $\mathrm{TiO}_{2}$ particles were 12.82 $\%, 7.65 \%$, and $0.18 \%$ at $\mathrm{pH}$ levels of 2,7 , and 12 , respectively. These results show that adsorption amounts of $\mathrm{Cr}(\mathrm{VI})$ through $\mathrm{TiO}_{2}$ particles at low $\mathrm{pH}$ level was much more than neutral $\mathrm{pH}$. The results have shown good agreement with previous works (Khalil et al., 1998; Chirwa et al., 2000; Colon et al., 2001; Uyguner and Bekbolet, 2004; Wang et al., 2008). The photocatalytic oxidation reaction depends on the amount of adsorption on the surface catalyst, therefore, at lower $\mathrm{pH}$ levels the reaction rate were highest.
Table 1: Surface characterization of $\mathrm{TiO}_{2}$

\begin{tabular}{lcccc}
\hline \multicolumn{1}{c}{ Name } & $S_{B E T}\left(\mathrm{~m}^{2} / \mathrm{g}\right)$ & $S_{t}\left(\mathrm{~m}^{2} / \mathrm{g}\right)$ & $V_{P}\left(\mathrm{~cm}^{2} / \mathrm{g}\right)$ & $D_{P}\left({ }^{0} \mathrm{~A}\right)$ \\
\hline $\mathrm{TiO}_{2}$ Degussa & 50.1 & 47 & 0.15 & 315 \\
$\mathrm{P} 25$ & & & & \\
\hline
\end{tabular}

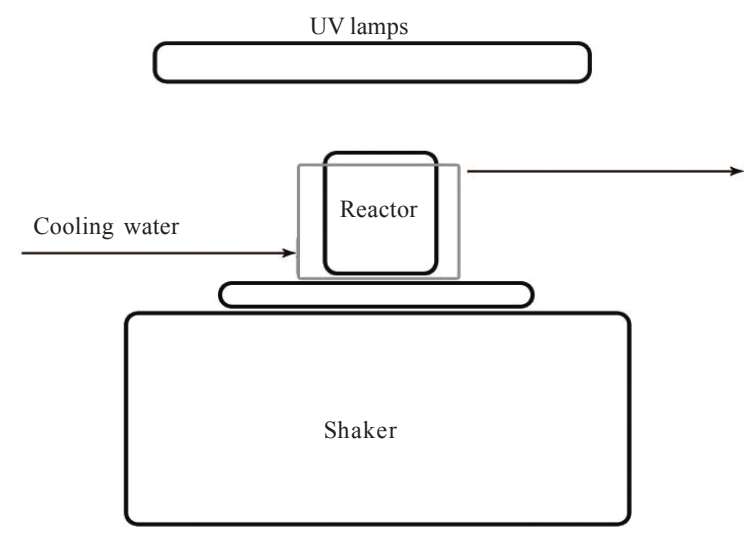

Fig. 1: Schematic diagram of the photocatalysis system

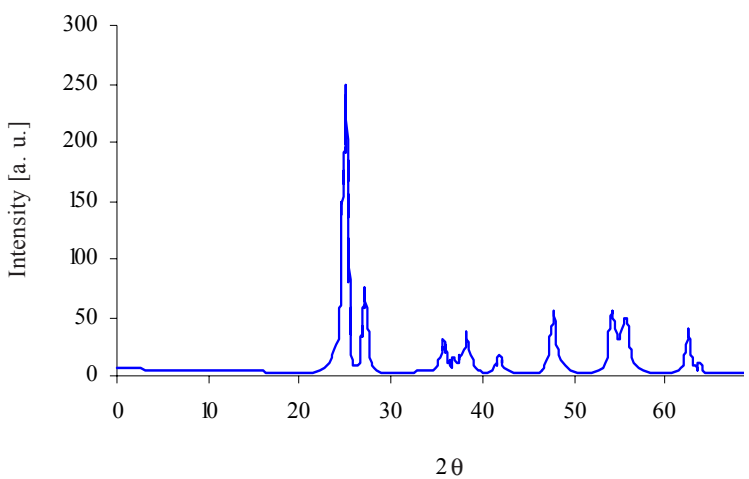

Fig. 2: XRD pattern of $\mathrm{TiO}_{2}$

Adsorption of TEP on $\mathrm{TiO}_{2}$

The effect of the $\mathrm{pH}$ values on adsorption behavior of TEP on $\mathrm{TiO}_{2}$ particles was also investigated. TEP adsorption percentage at different $\mathrm{pH}$ levels, which was calculated by Eq. 1, is shown in Table 2. At $\mathrm{pH}$ value of 12, the adsorption of TEP on $\mathrm{TiO}_{2}$ particles was highest; therefore, maximum adsorption amounts of TEP on $\mathrm{TiO}_{2}$ particles will be occurred at alkaline media. At $\mathrm{pH}$ value of 2, TEP will be protonized to carry the positive charge while the surface of $\mathrm{TiO}_{2}$ is electropositive. Therefore at low $\mathrm{pH}$ vales the adsorption of TEP on $\mathrm{TiO}_{2}$ particles does not favor. When $\mathrm{pH}$ goes to higher values, TEP comes to a neutral state and adsorption of TEP on $\mathrm{TiO}_{2}$ surfaces increased. 

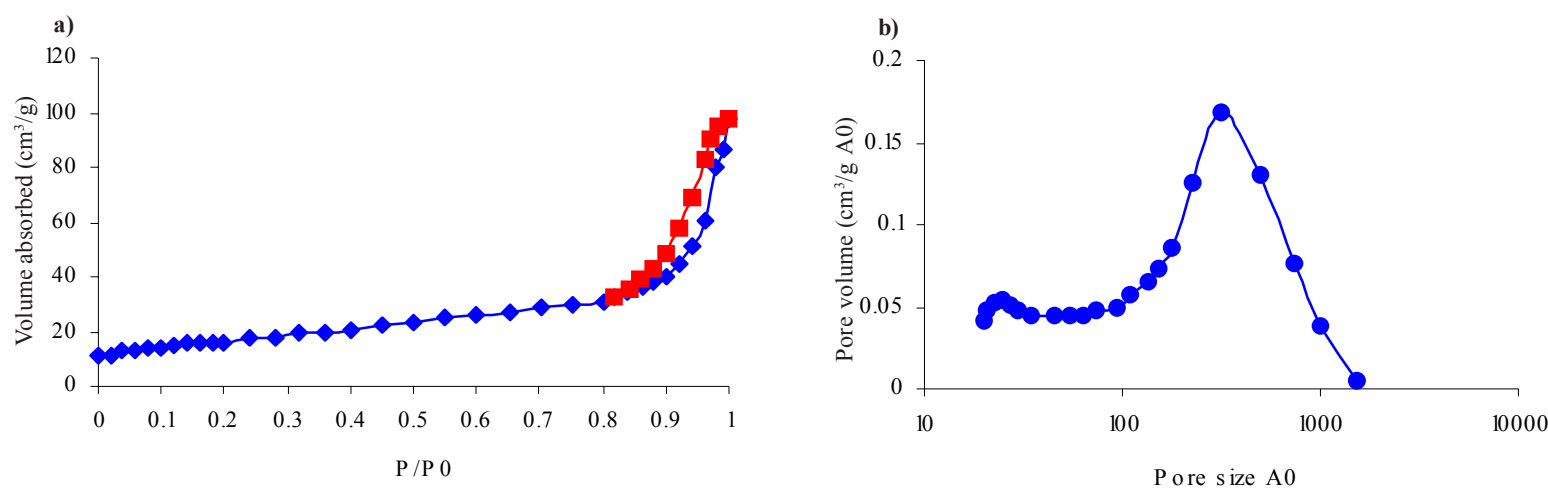

Fig. 3: a) $\mathrm{N}_{2}$ adsorption-desorption isotherm of $\mathrm{TiO}_{2}$ b) Pore size distribution of $\mathrm{TiO}_{2}$

Table 2: Adsorption of $\mathrm{Cr}(\mathrm{VI})$ and $\mathrm{TEP}$ on $\mathrm{TiO}_{2}$ surface $\left(\mathrm{TiO}_{2}=0.4 \mathrm{~g} / \mathrm{L}, \mathrm{Cr}(\mathrm{VI})=40 \mathrm{mg} / \mathrm{L}, \mathrm{TEP}=30 \mathrm{mg} / \mathrm{L}\right)$

\begin{tabular}{lccccc}
\hline $\mathrm{pH}$ value & 2 & 4 & 7 & 10 & 12 \\
$\mathrm{Cr}(\mathrm{VI})$ & $12.82 \pm 0.4$ & $7.65 \pm 0.3$ & $5.57 \pm 0.3$ & $1.34 \pm 0.1$ & $0.18 \pm 0.03$ \\
$\mathrm{TEP}$ & $14.01 \pm 0.5$ & $22.3 \pm 0.7$ & $24.7 \pm 0.7$ & $27.2 \pm 0.7$ & $34.02 \pm 0.7$ \\
\hline
\end{tabular}

Table 3: Co-adsorption of $\mathrm{Cr}(\mathrm{VI})$ and $\mathrm{TEP}$ on $\mathrm{TiO}_{2}$ surface $(\mathrm{TiO} 2=0.4 \mathrm{~g} / \mathrm{L}, \mathrm{Cr}(\mathrm{VI})=40 \mathrm{mg} / \mathrm{L}, \mathrm{TEP}=30 \mathrm{mg} / \mathrm{L})$

\begin{tabular}{lrrr}
\hline $\mathrm{pH}$ value & \multicolumn{1}{c}{4} & \multicolumn{1}{c}{7} \\
\hline $\mathrm{Cr}(\mathrm{VI})$ & $15.8 \pm 0.4$ & $8.7 \pm 0.3$ & $5.63 \pm 0.3$ \\
$\mathrm{TEP}$ & $14.21 \pm 0.7$ & $22.63 \pm 0.7$ & $24.47 \pm 0.7$ \\
\hline
\end{tabular}

Adsorption of $\mathrm{TEP}$ and $\mathrm{Cr}(\mathrm{VI})$ mixture on $\mathrm{TiO}_{2}$

Adsorption of TEP and $\mathrm{Cr}(\mathrm{VI})$ mixture on $\mathrm{TiO}_{2}$ were also investigated. As shown in table 3, at the presence of organic molecules (TEP), $\mathrm{Cr}$ (VI) adsorption efficiency decreased because of the competitive adsorption on the active sites of the catalyst while $\mathrm{pH}$ goes to higher values. In contrast at lower $\mathrm{pH}$ values, a significant enhancement were observed to adsorption of $\mathrm{Cr}(\mathrm{VI})$ on $\mathrm{TiO}_{2}$ surface. The results indicated that TEP had little influence on the adsorption of $\mathrm{Cr}(\mathrm{VI})$ on $\mathrm{TiO}_{2}$ particles while $\mathrm{Cr}(\mathrm{VI})$ had no influence on the adsorption of TEP on $\mathrm{TiO}_{2}$ particles in acidic media.

\section{Photocatalytic reactions}

Photocatalytic reduction of $\mathrm{Cr}(\mathrm{VI})$ by $\mathrm{UV}_{\mathrm{TiO}} \mathrm{T}_{2}$

The kinetic reaction were carried out in solutions at different $\mathrm{Cr}(\mathrm{VI})$ concentrations and $\mathrm{pH}$ levels to investigate the photocatalytic reduction of $\mathrm{Cr}(\mathrm{VI})$ by the $\mathrm{UV} / \mathrm{TiO}_{2}$ process. The reduced kinetic reaction of $\mathrm{Cr}(\mathrm{VI})$ at different initial concentration in solution, which suggests a first-order reaction, under constant $\mathrm{pH}$ value are shown in Fig. 4a. Several experimental results reported by previous researchers indicate that the apparent global rate of photocatalytic reduction reactions seem to follow the first-order kinetics. In addition, the Langmuir-Hinshelwood reaction rate was reported by Ku and Jung (2001) which had not been seen in this research.

The experimental results in Fig. $4 \mathrm{~b}$ showed a significant enhancement on the photocatalytic reduction rate of $\mathrm{Cr}(\mathrm{VI})$ while $\mathrm{pH}$ values decreased. However, the photocatalytic reduction of $\mathrm{Cr}(\mathrm{VI})$ was not detected when the $\mathrm{pH}$ value reached 10 and 12 . The value of $\mathrm{k}_{\mathrm{red}}$ can be calculated from the slop of plotting $\operatorname{Ln}\left[\mathrm{Cr}(\mathrm{VI}) / \mathrm{Cr}(\mathrm{VI})_{0}\right]$ versus time. The rate constants $\mathrm{k}_{\mathrm{red}}$ of $\mathrm{Cr}(\mathrm{VI})$ were $0.81,0.51$ and $0.38 \mathrm{~h} / \mathrm{r}$ at different $\mathrm{pH}$ values of 2 to 7 , respectively. These results can be correlated by Eq. 2 .

$\frac{d c}{d t}=-k_{\text {red }} C$

W here $k_{\text {red }}=1.217 \mathrm{pH}^{-0.6}$

Photocatalytic degradation of TEP by UV/TiO

During TEP oxidation process, intermediate materials such as diethyl phosphate and ethanol can be produced from TEP photocatalytic degradation, subsequently monoethyl phosphate can be formed from TEP and diethyl phosphate. At the final step, TEP and intermediate products degrade to phosphate which is 

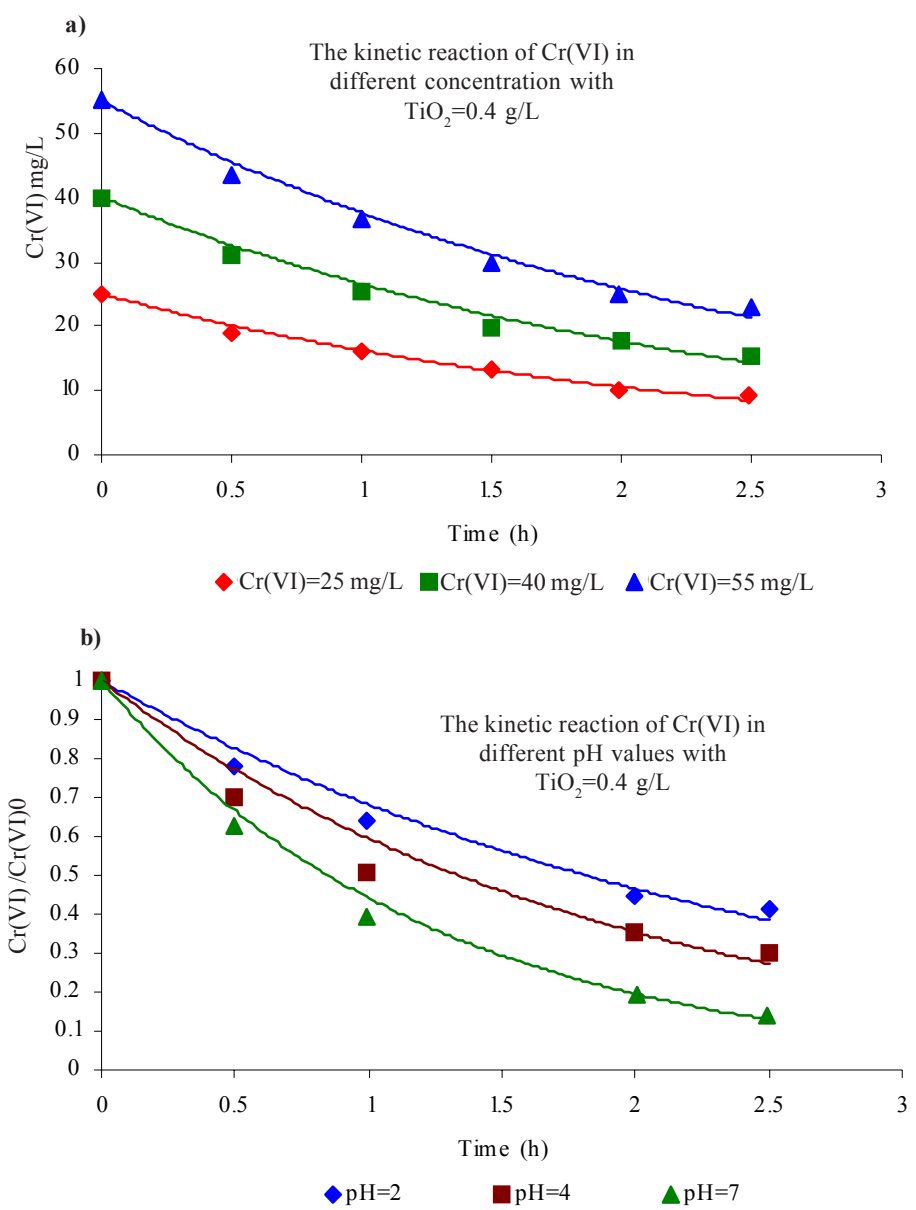

Fig. 4: The kinetic reaction of $\mathrm{Cr}(\mathrm{VI})$ in different a) concentration and b) $\mathrm{pH}$

known as the end of TEP degradation. At lower $\mathrm{pH}$ values, TEP is more stable; therefore, it hardly reached the criteria for ready potocatalytic degradation. The effect of $\mathrm{pH}$ values on reaction rates is shown in Fig. 5a. The experimental results showed the natural $\mathrm{pH}$ has a higher reaction rate. Degradation rate of TEP at higher $\mathrm{pH}$ values was lower than $\mathrm{pH}$ 7.0. This can be explained by the less adsorption amount of TEP on the $\mathrm{TiO}_{2}$ at acidic $\mathrm{pH}$ compared $\mathrm{pH} 7$; therefore, the adsorption process plays an important role in photocatalytic reactions.

In Fig. 5b, the effect of TEP concentration on kinetic degradation was studied at the $\mathrm{pH}$ level of 7. A little trace phosphate were observed at earlier stage of the potocatalytic reaction; because, phosphate is formed after the degradation of TEP, diethyl phosphate and monoethyl phosphate. After lag time, phosphate amount suddenly increased up to final concentration. These lags were $21.1,35$, and $47 \mathrm{~min}$ for 10,30 and 50 $\mathrm{mg} / \mathrm{L}$ of TEP concentration in solution, respectively. Also, the zero-order kinetic can be fitted in different concentrations of TEP at the $\mathrm{pH}$ value of 7 . The final equation is:

$\frac{d C_{\text {phosphate }}}{d t}=k_{\text {red }} \quad t>t_{\text {lag }}$

Where, $k_{\text {red }}=0.756 C_{T E P_{0}}^{-0.29}(h / r)$

And $t_{\text {lag }}=0.112 C_{T E P_{0}}^{0.492}(h r)$ 

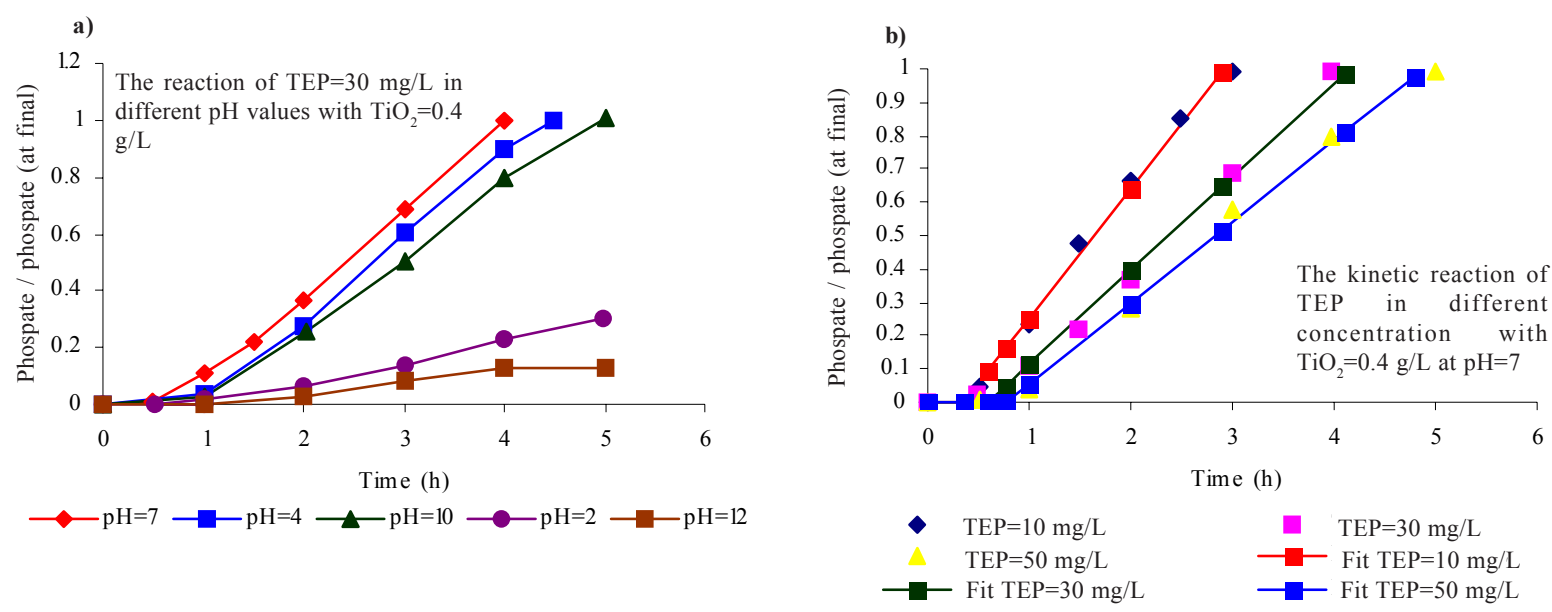

Fig. 5: The kinetic reaction of TEP in different a) concentration and b) $\mathrm{pH}$

a)
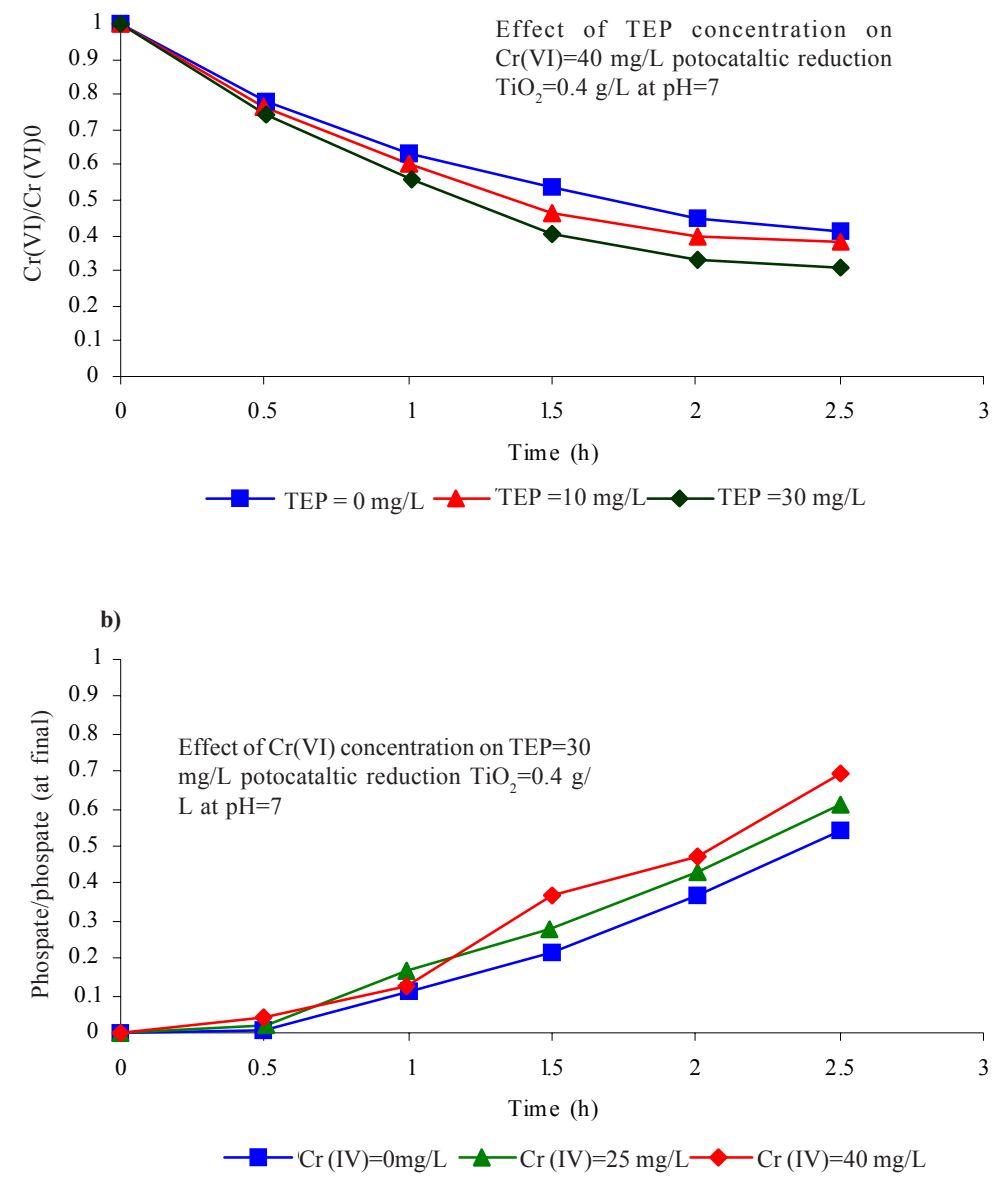

Fig. 6: Effect of TEP on a) $\mathrm{Cr}(\mathrm{VI})$ potocatalytic reduction and b) $\mathrm{Cr}(\mathrm{VI})$ on TEP potocatalytic 

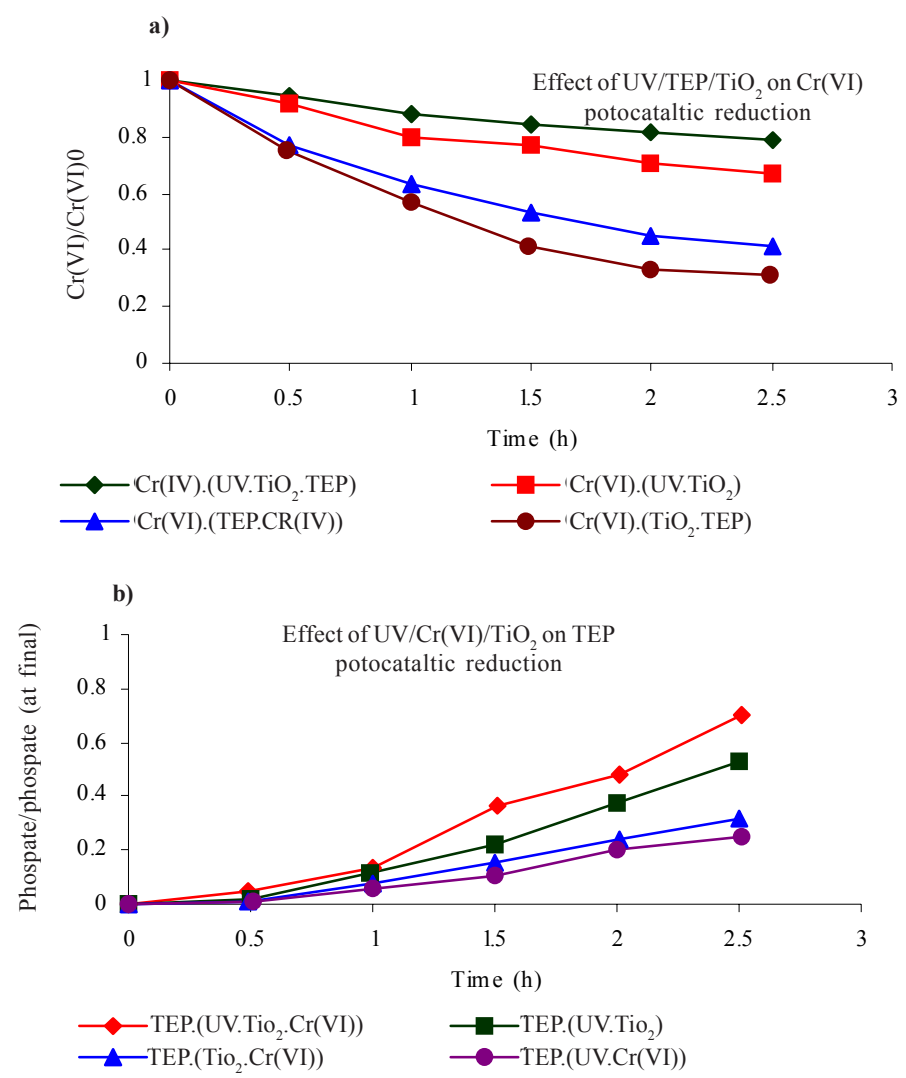

Fig. 7: Effect of parameter conditions on a) $\mathrm{Cr}(\mathrm{VI})$ potocatalytic reduction and b) TEP potocatalytic degradation

Photocatalytic oxidation on TEP/Cr(VI) mixture

The photocatalytic degradation of the TEP/Cr (VI) mixture was investigated at the $\mathrm{pH}$ value of 7.0 using the $\mathrm{UV} / \mathrm{TiO}_{2}$ process with $\mathrm{TiO}_{2}$. A decreasing in TEP and $\mathrm{Cr}$ (VI) concentration with time and synergic effect was observed as shown in Fig. 6. The rate constants of $\mathrm{Cr}$ (VI) photocatalytic reduction were $0.38,0.44$ and 0.51 $\mathrm{h} / \mathrm{r}$ at TEP concentrations of 0,10 and $30 \mathrm{mg} / \mathrm{L}$, respectively. Results showed the photocatalytic reduction rate of $\mathrm{Cr}(\mathrm{VI})$ subsequently increased. When TEP was mixed with $\mathrm{Cr}(\mathrm{VI})$ in a $\mathrm{UV} / \mathrm{TiO}_{2}$ system, the possibility of the capture of an electron by $\mathrm{Cr}(\mathrm{VI})$ could be promoted while the parts of the hole could be scavenged by TEP and produced intermediate materials such as ethanol. The effect of $\mathrm{Cr}(\mathrm{VI})$ concentration on the potocalatilytic degradation of TEP at the $\mathrm{pH}$ value of 7, are shown in Fig. 6b. The potocatalytic degradation of TEP in the $\mathrm{Cr}(\mathrm{VI})$ / TEP system was faster in compared to the TEP single system conducted with the $\mathrm{UV} / \mathrm{TiO}_{2}$ process. When $\mathrm{Cr}(\mathrm{VI})$ concentrations in solution increased, the rate constants of TEP degradation increased from 0.201 to $0.33 \mathrm{~h} / \mathrm{r}$.

Siemon et al. (2002) explained an electron-shuttle mechanism which $\mathrm{Cr}(\mathrm{VI})$ is continuously reduced and reoxidized by valence band holes, he was previously invoked to explain the results in pure water. This mechanism is non-operative in the presence of a reducing agent that can strongly compete for the holes with reduced $\mathrm{Cr}(\mathrm{VI})$ species, producing a synergistically cooperative effect. A synergetic effect between the photocatalytic reduction of $\mathrm{Cr}(\mathrm{VI})$ and the TEP degradation was observed. Previous researches have reported this accelerating effect (Colon et al., 2001).

\section{Reactions on $\mathrm{TEP} / \mathrm{Cr}(\mathrm{VI}) / \mathrm{UV} / \mathrm{TiO}$, mixture}

The potocatalytic reaction rate in the $\mathrm{Cr}(\mathrm{VI}) / \mathrm{TEP}$ mixture solution without $\mathrm{TiO}_{2}$ under the irradiation of UV light and with $\mathrm{TiO}_{2}$ under visible light were investigated at the $\mathrm{pH}$ value of 7 with continuous stirring. Results are shown in Fig. 7 which indicate that 
the reaction rate of TEP under visible light with $\mathrm{TiO}_{2}$ and the reduction rate of $\mathrm{Cr}(\mathrm{VI})$ under UV light without $\mathrm{TiO}_{2}$ had the lowest rates. In the case of $\mathrm{TiO}_{2}$ present, adsorption had most important role on removing of $\mathrm{Cr}(\mathrm{VI})$ and also, the thermal reaction between produced intermediate materials and $\mathrm{Cr}(\mathrm{VI})$ can cause $\mathrm{Cr}(\mathrm{VI})$ to reduce:

$$
\begin{gathered}
5 \mathrm{CrO}_{4}^{-1}+2 \mathrm{C}_{2} \mathrm{H}_{3} \mathrm{OH}+2 \mathrm{OH}^{+} \rightarrow \\
5 \mathrm{Cr}(\mathrm{III})+4 \mathrm{CO}_{2}+14 \mathrm{H}_{2} \mathrm{O}
\end{gathered}
$$

The main degradation process for TEP in water is hydrolysis which may increase with the irradiation of UV light in a $\mathrm{Cr}(\mathrm{VI}) / \mathrm{TEP}$ system in the absence of $\mathrm{TiO}_{2}$. Photocatalytic degradation of TEP and intermediates on the surface of titanium dioxide in water suspension can be done via reactions between $\mathrm{Cr}(\mathrm{VI})$ and hole:

$$
\begin{aligned}
& 5 \mathrm{TEP}+\mathrm{Cr}(\mathrm{VI}) \rightarrow \mathrm{Cr}(\mathrm{III})+3 \mathrm{TEP} P^{+}, \\
& \mathrm{TEP}^{+} \stackrel{+\mathrm{H}_{2} \mathrm{O}, \mathrm{k}}{\longrightarrow} \mathrm{TEP}{ }^{*}+\mathrm{H}_{3} \mathrm{O}^{+}
\end{aligned}
$$

\section{CONCLUSION}

The following results may be achieved from the above work in which the photocatalytic oxidation of the $\mathrm{Cr}(\mathrm{VI}) / \mathrm{TEP}$ mixture have been studied in different conditions. It was found that the capacity of adsorption is increased with the decreasing of $\mathrm{pH}$ for $\mathrm{Cr}(\mathrm{VI})$ and the increasing of $\mathrm{pH}$ for TEP. Also, co-adsorption of $\mathrm{TEP} / \mathrm{Cr}(\mathrm{VI})$ can cause to increasing the $\mathrm{Cr}(\mathrm{VI})$ adsorption on the $\mathrm{TiO}_{2}$ surface. The highest potocatalytic reaction rate was observed at neutral $\mathrm{pH}$ and acidic $\mathrm{pH}$ for TEP and $\mathrm{Cr}(\mathrm{VI})$, respectively. The synergic effect between the degradation of TEP and the reduction of $\mathrm{Cr}(\mathrm{VI})$ is demonstrated in a system containing $\mathrm{Cr}(\mathrm{VI})$ and $\mathrm{TEP}$ by $\mathrm{UV} / \mathrm{TiO}_{2}$. The results show that the reaction rate between $\mathrm{Cr}(\mathrm{VI})$ and TEP in the absence of $\mathrm{TiO}_{2}$ and $\mathrm{UV}$ light is at $\mathrm{pH}$ level 7.

\section{ACKNOWLEDGEMENTS}

The authors thank the financial support of Department of Chemical Engineering, Amirkabir University of Technology (Tehran Polytechnic) and Department of Civil Engineering, Iran University of Science and Technology, Tehran, Iran as well as specially Dr. Mohsen Saeedi and Mr. Pooya Arbab for their cooperation.

\section{REFERENCES}

Atafar Z, Mesdaghinia A, Nouri J, Homaee, M.; Yunesian, M., (2010). Effect of fertilizer application on soil heavy metal concentration. Environ. Monitor. Assess., 160 (1-4), 83-89
(7 pages).

Ambashta, R. D.; Sillanpaa, M., (2010). Water purification using magnetic assistance: A review. J. Hazard. Mater., 180 (1-3), 38-49 (12 pages).

Andreozzi, R.; Caprio, V.; Insola, A.; Marotta, R., (1999). Advanced oxidation processes (AOP) for water purification and recovery. Catal. Today, 53 (1), 51-59 (9 pages).

Bang, S.; Patel, M.; Lippincott, L.; Meng, X., (2005). Removal of arsenic from groundwater by granular titanium dioxide adsorbent. Chemosphere, 60 (3), 389-397 (9 pages).

Chenthamarakshan, C. R.; Rajeshwar, K.; Wolfrum, E. J., (2000). Heterogeneous photocatalytic reduction of $\mathrm{Cr}(\mathrm{VI})$ in UViradiated titania suspensions: Effect of protons, ammonium ions, and other interfacial aspects. Langmuir, 16 (6), 27152720 (6 pages).

Chirwa, E. N.; Wang, Y. T., (2000). Simultaneous chromium (VI) reduction and phenol degradation in an anaerobic consortium of bacteria. Water Res., 34 (8), 2376-2384 (9 pages).

Colon, G.; Hidalgo, M. C.; Navýo, J.A., (2001). Influence of carboxylic acid on the photocatalytic reduction of $\mathrm{Cr}(\mathrm{VI})$ using commercial $\mathrm{TiO}_{2}$. Langmuir, 17 (22), 7174-7177 (4 pages).

Doong, R. A.; Chang, W. H., (1997). Photoassisted titanium dioxide mediated degradation of organophosphorus pesticides by hydrogen peroxide. J. Photochem. Photobiol. A., 107 (13), 239-244 (6 pages).

Gerven, T. V.; Mul, G.; Moulijn, J.; Stankiewicz, A., (2007). A review of intensification of photocatalytic process. Chem. Eng. Process, 46 (9), 781-789 (9 pages).

Gharbani, P.; Khosravi, M.; Tabatabaei, S. M.; Zare, K.; Dastmalchi, S.; Mehrizad, A., (2010). Degradation of trace aqueous 4-chloro--nitrophenol occurring in pharmaceutical industrial wastewater by ozone. Int. J. Environ. Sci. Tech., 7 (2), 377-384 (8 pages).

Jiang, F.; Zheng, Z.; Xu, Z.; Zheng, S.; Guo, Z.; Chen, L., (2006). Aqueous $\mathrm{Cr}(\mathrm{VI})$ photo-reduction catalyzed by $\mathrm{TiO}_{2}$ and sulfated $\mathrm{TiO}_{2}$. J. Hazard. Mater., 134 (1-3), 94-103 (10 pages).

Joseph, C. G.; Puma, G. L.; Bono, A.; Krishnaiah, D., (2009). Sonophotocatalysis in advanced oxidation process: A short review. Ultrason. Sonochem., 16 (5), 583-589 (7 pages).

Kerzhentsev, M.; Guillard, C.; Herrmann, J. M.; Pichat, P., (1996). Photocatalytic pollutant removal in water at room temperature: case study of the total degradation of the insecticide fenitrothion (phosphorothioic acid O,O-dimethylO-(3-methyl-4-nitro-phenyl) ester). Catal. Today, 27 (1-2), 215-220 ( 6 pages).

Khalil, L. B.; Mourad, W. E.; Rophael, M.W., (1998). Photocatalytic reduction of environmental pollutant $\mathrm{Cr}(\mathrm{VI})$ over some semiconductors under UV/visible light illumination. Appl. Catal. B-Environ., 17 (3), 267-273 (7pages)

Kim, C.; Zhou, Q.; Deng, B.; Thornton., E. C.; Xu, H., (2001). Chromium (VI) reduction by hydrogen sulfide in aqueous media: Stoichiometry and kinetics. Environ. Sci. Tech., 35 (11), 2219-2225 (7 pages).

Kozlova, E. A.; Smirniotis, P. G.; Vorontsov, A.V., (2004). Comparative study on photocatalytic oxidation of four organophosphorus simulants of chemical warfare agents in aqueous suspension of titanium dioxide. J. Photochem. Photobio. A., 162 (2-3), 503-511 (9 pages).

$\mathrm{Ku}$, Y.; Jung, I. L., (2001). Photocatalytic reduction of Cr (VI) 
in aqueous solutions by UV irradiation with the presence of titanium dioxide. Water Res., 35 (1), 135-142 (8 pages).

Malato, S.; Blanco, J.; Fernandez-Alba, A. R.; Aguera, A., (2000). Solar photocatalytic mineralization of commercial pesticides: acrinathrin. Chemosphere, 40 (4), 403-409 (7 pages).

Nouri, J.; Lorestani, B.; Yousefi, N.; Khorasani, N.; Hasani, A. H.; Seif, S.; Cheraghi, M., (2011). Phytoremediation potential of native plants grown in the vicinity of Ahangaran lead-zinc mine (Hamedan, Iran). Environ. Earth Sci., 62 (3), 639-644 (6 pages).

Percherancier, J. P.; Chapelon, R.; Pouyet, B., (1995). Semiconductor-sensitized photodegradation of pesticides in water: the case of carbetamide. J. Photochem. Photobiol. A., 87 (3), 261-266 (6 pages).

Sun, B.; Vorontsov, A.V.; Smirniotis, P. G., (2011). Parametric studies of diethyl phosphoramidate photocatalytic decomposition over $\mathrm{TiO}_{2}$. J. Hazard. Mater., 186 (2-3), 1147 1153 (7 pages).

Siemon, U.; Bahnemann, D.; Testa, J. J.; Rodriguez, D.; Litter, M. I.; Bruno, N., (2002). Heterogeneous photocatalytic reactions comparing $\mathrm{TiO}_{2}$ and $\mathrm{Pt} / \mathrm{TiO}_{2}$. J. Photochem. Photobiol. A: Chem., 148 (1-3), 247-255 (9 pages).

Thiruvenkatachari, R.; Vigneswaran, R.; Moon, S., (2008). A review on $\mathrm{UV} / \mathrm{TiO}_{2}$ photocatalytic oxidation process. Korean
J. Chem. Eng., 25 (1), 64-72 (9 pages).

Tompsett G. A.; Bowmaker G. A.; Cooney R. P.; Metson J. B.; Rogers K. A., Seakins J. M., (1995). The raman spectrum of brookite $\mathrm{TiO}_{2}$. J. Raman Spectrosc., 26 (1), 57-62 (6 pages).

Uyguner, C. S.; Bekbolet, M., (2004). Evaluation of humic acid, chromium (VI) and $\mathrm{TiO}_{2}$ ternary system in relation to adsorptive interactions. Appl. Catal. B-Environ., 49, 267-275 (9 pages).

Wang, L.; Wang, N.; Zhu, L.; Yu, H.; Tang, H., (2008). Photocatalytic reduction of $\mathrm{Cr}(\mathrm{VI})$ over different $\mathrm{TiO}_{2}$ photocatalysts and the effects of dissolved organic species. J. Hazard. Mater., 152 (1), 93-99 (7 pages).

Xu, X. R.; Li, H. B.; Gu, J. D., (2006). Simultaneous decontamination of hexavalent chromium and methyl tert -butyl ether by UV/TiO2 Process. Chemosphere, 63 (2), 254-260 (7 pages).

Wuana, R. A.; Okieimen, F. E.; Imborvungu, J. A., (2010). Removal of heavy metals from a contaminated soil using chelating organic acids. Int. J. Environ. Sci. Tech., 7 (3), 485-496 (12 pages).

Zhang, H. Z.; Banfield, J. F., (2000). Understanding polymorphic phase transformation behavior during growth of nanocrystalline aggregates: insights from $\mathrm{TiO}_{2}$. J. Phys. Chem. B., 104 (15), 3481-3487 (7 pages).

\section{AUTHOR (S) BIOSKETCHES}

Fathizadeh, M., Ph.D., Department of Chemical Engineering, Amirkabir University of Technology (Tehran Polytechnic), Hafez Ave., P.O. Box 15875-4413, Tehran, Iran. Email: M.Fathizade@aut.ac.ir

Fakhraee, H., Associate Professor, Department of Civil Engineering, University of Science and Technology, Tehran, Iran.

Email: Fakhraee@iust.ac.ir

Aroujalian, A., Professor, Department of Chemical Engineering, Amirkabir University of Technology (Tehran Polytechnic), and Food Process Engineering and Biotechnology Research Center, Amirkabir University of Technology (Tehran Polytechnic), Hafez Ave., P.O. Box 15875-4413, Tehran, Iran. Email: aroujali@aut.ac.ir

How to cite this article: (Harvard style)

Fathizadeh, M.; Fakhraee, Aroujalian, A., (2011). Decontamination of hexavalent chromium and tri-ethyl phosphate stimulants through photacatalytic oxidation. Int. J. Environ. Sci. Tech., 8 (4), 863-871. 